\title{
Lithium Including Mixed Sodium Inside Graphene Oxide (GO) as Anodic Electrodes for ion Batteries
}

\author{
SAMIRA BAGHERI ${ }^{1}$, MAJID MONAJJEMI ${ }^{2 *}$, ALIREZA ZIGLARI ${ }^{1}$ \\ and AFSHIN TAGHVA MANESH \\ 'Department of Chemistry, College of science, Central Tehran Branch, \\ Islamic Azad University, Tehran, Iran. \\ ${ }^{2}$ Department of Chemical Engineering, Central Tehran Branch, \\ Islamic Azad University, Tehran, Iran. \\ Corresponding Author: m_monajjemi@srbiau.ac.ir \\ http://dx.doi.org/10.13005/ojc/340248
}

(Received: October 21, 2017; Accepted: January 20, 2018)

\begin{abstract}
Graphene oxide has a great potential as a suitable material for anodic sodium ion battery (NIBs) due to its unique behavior. The calculated reversible of lithium ion capacity of GO/ Li \& Na / GO based anodic materials are widely improved comparing to the conventional graphite-based anodic materials. By this investigation GO sheets have been localized into the graphene as an item for enhancing electrochemical \& Physical ratio. Moreover, the structure of GO/Li\& Na/GO can be used for improving the capacities and electronics transport in the GO sheets-based NIBs. Therefore, these modifications of $\mathrm{GO}$ sheet and designing of $\mathrm{GO} / \mathrm{Li} \& \mathrm{Na} / \mathrm{GO}$ structures provide a strategy for increasing the performance of GO-based anode. GO/Li \& Na/GO could also be accomplished into the free- standing anodes without any of binders or current's collectors, which will leads to increased energies densities of overall battery's designing.
\end{abstract}

Keywords: Graphene oxide (GO), Anodic materials, Lithium ion batteries.

\section{INTRODUCTION}

Sodium-ion battery is a type of re-chargeable battery which uses sodium-ions as its charge carriers and is very similar to LIBTs in many ways. $\mathrm{Na}$ ions are $33 \%$ larger in diameter and 2.1 times heavier within lower gravimetric capacities than Li-ion batteries ${ }^{1}$. In addition $\mathrm{Na}$ metals are more active than $\mathrm{Li}$ with the standard electrode potentials which is $\sim 0.3 \mathrm{~V}$ higher than $\mathrm{Li}$.

By the Sony it has been realized a commercialization of $\mathrm{xC} 6 / \mathrm{Li}_{1-\mathrm{x}} \mathrm{CoO}_{2}$ cells ${ }^{1}$ reaction and mechanism in 1991. LIBs are representative energies storage devices based on electrochemical energies, widely used in small grid storage systems.

This is an 2 Open Access article licensed under a Creative Commons Attribution-NonCommercial-ShareAlike 4.0 International License (https://creativecommons.org/licenses/by-nc-sa/4.0/ ), which permits unrestricted NonCommercial use, distribution and reproduction in any medium, provided the original work is properly cited. 
Within discovery of high quality reversible, low-voltage ${ }^{1}$ Li-intercalations carbonaceous ${ }^{1}$ material, the suitable electronic and chemical performances of LIBs concerning energies and power densities ${ }^{1}$, as well as the progress in the cell designing and manufacturing, has been made LIBs extremely successful for mobile equipment.

Although; the $\mathrm{Na}^{+}$cation has a greater radius than the $\mathrm{Li}^{+}$cation, that causes a few of the superior LIB anode's materials un-suitable for $[\mathrm{NIBs}]^{2}$, concerns regarding ${ }^{2}$ the extra availability of lithium resources ${ }^{2}$ is raising. A sodium ${ }^{2}$ ion battery has drawn increasing attention ${ }^{3}$ due to $\mathrm{Na}$ is a abundant ${ }^{3}$ element and shares ${ }^{2}$ common properties within $\mathrm{Li}^{2-4}$, specially, graphite ${ }^{5}$ is used ${ }^{6}$ for anodic electrodes in the present commercial ${ }^{7}$ LIBs, while those have been reported for having a very low capacity $^{6}$ of when used as an anodic electrode for $\mathrm{NIBs}^{5-7}$.

Both disordering carbons and Nano-flakes ${ }^{8}$ (CNFs) exhibited a high $\mathrm{Na}$ intercalation ${ }^{9}$ capacities and emerges $^{8}$ as the leading candidates for NIB applications ${ }^{8,9}$. In this study we tried to build a model for GO for investigating the mechanisms for $\mathrm{Na}$ intercalation ${ }^{9}$ into the layered domains ${ }^{9}$. Although, the mechanism ${ }^{7}$ of $\mathrm{Na}^{+}$cation inserting into disturbed carbons are still controversial ${ }^{10}$. It is confirmed that a bigger interlayer distances ${ }^{11}$ of those carbons, which are bigger than interlayers distances of graphite, help $\mathrm{Na}^{+}$ion intercalation. Consequently, the defects might be enhanced the $\mathrm{Na}^{+}$ intercalations through the strong bonding energies for overcoming the van der Waals energies between graphene sheets ${ }^{12}$. In this study it has been evaluated the reliabilities of several semi-empirical corrections and vdW exchange's correlation functional for determining the optimal12 methods of this work. Graphited electrodes are currently the most general materials used for the anodes of commercial ${ }^{12}$ batteries due to its capabilities for reversible ${ }^{12}$ lithium intercalation ${ }^{13}$ in a layered crystal that represent maximum theoretical sodium storage capacity ${ }^{13}$.

NIBs includes of a positive electrode and a negative electrode with suitable conducting electrolytes where store ${ }^{14}$ electric energies as the forming of Na-intercalations compounds ${ }^{11}$. Electrodes $^{12}$, separator ${ }^{13}$, and electrolytes are the major components ${ }^{14}$ in the NIB batteries which the anodic electrodes play important behavior in the mechanism of those kind devices ${ }^{12,13}$.

The structures and properties ${ }^{14}$ of graphitic oxide depends on a synthesis method or degree of oxidation ${ }^{13}$. In addition graphite, typically preserves ${ }^{14}$ the layer structures of those parent graphite, but the layers are buckled ${ }^{14}$ and the interlayer's spacing ${ }^{14}$ is about two times bigger than the graphite that provides suitable environment for sodium diffusion in a NIBs ${ }^{11}$

The detailed ${ }^{15}$ structures are still not described because of the strong disordering and irregular ${ }^{13}$ packing of those layers ${ }^{12}$. GO layer is about $1.1 \pm 0.2 \mathrm{~nm}$ thick ${ }^{10,11}$. STM spectroscopy indicates the presences of some regions ${ }^{14}$ where the oxygen atoms are arranged ${ }^{12}$ in a rectangular ${ }^{13}$ pattern within lattice constant ${ }^{14} 0.26 \mathrm{~nm} \times 0.42 \mathrm{~nm}^{11}$ the edges ${ }^{15}$ of one layer is terminated with $\mathrm{COOH}$ and $\mathrm{CO}$ groups ${ }^{10}$. GO exfoliates ${ }^{15}$ and decomposes ${ }^{16}$ when heated (rapidly) at moderately ${ }^{14}$ high temperatures within the formation ${ }^{14}$ of finely dispersed ${ }^{13}$ amorphous carbons, somewhat similar for activating carbon ${ }^{12}$.

$$
\mathrm{XRD}^{14}, \mathrm{FTIR}^{15} \text {, } \text { Raman }^{16}, \mathrm{XPS}^{15}, \mathrm{AFM}^{14} \text {, }
$$

$\mathrm{TEM}^{13}$, etc. are some general techniques for characterizing the GO samples ${ }^{13}$. Since the distributions of oxygen's functionalities on GO sheets are poly-disperse fractionations methods using emulsion ${ }^{16}$ stabilizations can be used for characterizing and separating "GO" on the basis of oxidation ${ }^{14}$. During of the charging step, the "NIBs" sodium ions released ${ }^{15}$ from the cathodes electrodes to move inside the electrolyte and is inserted ${ }^{16}$ into the anodes. Upon ${ }^{15}$ discharging, sodium ions are extracted ${ }^{15}$ from the anode electrodes and move back to the cathode ${ }^{14}$. Although the electrolytes establishes ${ }^{15}$ high ionic conductivities between anodes and cathodes, this electrolyte is not responsible ${ }^{15}$ for the conduction ${ }^{16}$ of those electrons ${ }^{16}$ and the half of reaction, so will move through the extra ${ }^{14}$ external wires.

Several experiments ${ }^{16}$ have been performed for confirming the utilization of graphene nano-sheets ${ }^{16}$ and nano-ribbons ${ }^{17}$ for enhancing 
lithium capacity to improve the recharge cyclic performances. Furthermore semi-empirical ${ }^{15}$ and molecular ${ }^{17}$ orbital calculations have been used for investigating sodium ion storage states among the graphene sheets ${ }^{15}$, as well as some heteroatomsubstituted carbon materials ${ }^{16}$. There are several studies on anodic materials ${ }^{17-20}$ and most of them focus on carbons and inorganic materials ${ }^{18}$.

Discharging and charging of LIBTs in graphitized ${ }^{19}$ carbon is well investigated up to now ${ }^{21-24}$. It has also been established how the repulsive ${ }^{19}$ interaction can result in the pure stages during intercalation ${ }^{22}$. Although efforts have been tried for finding suitable replacements ${ }^{23}$, now days only the carbonaceous goods are used for the commercial anodes ${ }^{25}$. Carbonaceous properties widely depends on the preparing materials such as precursor or heat treatment ${ }^{26}$

By this work, charging or dis-charging of Na-cations have been investigated ${ }^{24}$ in Graphite oxide (GO) with the (+) electrode reaction ${ }^{25}$ as: $\mathrm{NaCoO}_{2} \leftarrow \mathrm{Na1}-\mathrm{x} \mathrm{CoO}_{2}+\mathrm{x} \mathrm{Na}++\mathrm{x} \bar{e}$ and the (-) electrode mechanism as: $x \mathrm{GO}+\mathrm{xNa}^{+}+\mathrm{x} \bar{e} \leftarrow \mathrm{x}$ $\mathrm{NaGO}$, while the whole reaction is: $\mathrm{NaCoO}_{2}+x \mathrm{xO}$ $\leftarrow \mathrm{Na}_{1-\mathrm{x}} \mathrm{CoO}_{2}+\mathrm{x} \mathrm{Na} \mathrm{GO}$. It has been predicted that a sodium atom is stored ${ }^{26}$ through two mechanisms: intercalation ${ }^{26}$ and alloying ${ }^{27}$. GO similar Graphite is applied as small band gap semi-metals because of its excellent conduction treatment under the influence ${ }^{27}$ of electrical fields ${ }^{28,29}$. Interlayer forces ${ }^{30}$ are nothing, and the distances among GO layers ${ }^{31}$ are large allowing ${ }^{29} \mathrm{Na}$-ions for diffusing between $\mathrm{GO}$ sheets $^{22}$. Electrical conductivity of the Na-GO increases, Because of the electron donor nature of the $\mathrm{Na}^{33}$. Based on some previous studies we have used several methods to simulate the NIBs and calculated the NMR, solvent effect ${ }^{24}$, voltages, charges and physical properties of our model ${ }^{32-43,}$ 77-81 .Typical commercially ${ }^{31}$ used sodium -ion battery including several interconnected ${ }^{32}$ electrochemical cells, where each one consist of a GO anode, a cathode formed ${ }^{30}$ by sodium metal oxide $\left(\mathrm{NaCoO}_{2}\right)$ and electrolyte same as $\mathrm{NaPF}_{6}$ embedded in a separator felt ${ }^{29}$.

\section{$\mathrm{Na}^{+}$Diffusion}

Diffusion of $\mathrm{Na}^{+}$in the cells determine the key performance ${ }^{31}$ of $\mathrm{Na}$-ion batteries cells, with the charge and discharge rates, practical and cycling capacities and stabilities respectively. The governing ${ }^{45}$ equations describing ${ }^{44}$ the diffusion ${ }^{44}$ process are famous as Fick's law as: $j i=(1)-D_{i} \nabla C \&$ (2): $\frac{\sigma C_{i}}{\sigma t}=\nabla \cdot\left(D \nabla C_{i}\right)$ which $j i$ is an ion in flux condition, molcm ${ }^{-2} \mathrm{~s}^{-1}$, are diffusivities of solute $(i=1,2), \mathrm{cm}^{2} \mathrm{~s}^{-1}$ and $\mathrm{C}_{\mathrm{i}}$ are concentrations of species $\mathrm{i},(\mathrm{molcm} 3)^{44}$. The proportionalities ${ }^{44}$ factors $D$ are the diffusivities or diffusion coefficients as $D_{i}=\frac{K_{B} T}{6 \pi \mu R}(3)^{44,45}$. In condensed systems both liquid \& solid, diffusion ${ }^{45}$ is governed ${ }^{45}$ by random particles, leads to a position exchanges by its neighbor. The kinetic parameter of these processes are temperatures depend to an Arrhenius types relationships rate $\approx \exp \left(-\frac{\Delta G}{k_{B} T}\right)(4)^{46}$

In liquid phase, the temperature related of diffusion ${ }^{45}$ is less than the solid form. There are no successful ${ }^{44}$ first-principle calculations which have been made, because of in-sufficient interpretation of the liquid structure ${ }^{44}$. Therefore, an easy expression ${ }^{44}$ is gotten from Stoke's drag law which is used as an alternative ${ }^{45}$ for a diffusivities expression in the liquids ${ }^{55}$ frequently (Eq. 3 ). $\mathrm{Na}^{+}$is quite big comparing to electrons ${ }^{46}$; the radius of a $\mathrm{Na}$-ion is larger than that of an electron (electron: $\left.10^{\prime 22} \mathrm{~m}\right)^{46}$. The motions of $\mathrm{Na}$-ions are strongly impeded through the ions as discussed below ${ }^{47}$.

\section{Cathode materials}

In an extended approach they can be classified as 1- Layered compounds $\mathrm{NaMO}_{2}$ $(\mathrm{M}=\mathrm{Co}, \mathrm{Ni}, \mathrm{Mn})$, 2- Spinel compounds $\mathrm{NaM}_{2} \mathrm{O}_{4}$ ( $\mathrm{M}=\mathrm{Mn}$, etc.) 3-Olivine compounds $\mathrm{NaMPO}_{4}$ $\left(\mathrm{M}=\mathrm{Fe}, \mathrm{Mn}, \mathrm{Ni}, \mathrm{Co}\right.$, etc.). When a Na-ion diffuses ${ }^{56}$ out of the cathode during the charges cycles the valence states of the transition ${ }^{46}$ metal ion change as; the $\mathrm{Fe}^{++}$to $\mathrm{Fe}^{+++}$. The reaction in cathode can be written as: (Figure 1)

$\mathrm{NaFePO}_{4}-\mathrm{xNa}^{+}-\mathrm{xe}^{-} \leftarrow \mathrm{x} \mathrm{NaPO}_{4}+(1-\mathrm{x}) \mathrm{NaPO}_{4}$ and $\mathrm{Fe}^{2+}-\mathrm{e}^{-\leftarrow} \rightarrow \mathrm{Fe}^{3+}$

\section{Anode materials}

In the anode, $\mathrm{Na}^{+}$are found to be the suitable electropositive particles with large reversible capacities. However, due to safety considerations ${ }^{51}$, metallic $\mathrm{Na}$ has been substituted by various carbonaceous materials such as GO. 
GO-sodium anode has much lower gravimetric and volumetric energies density than pure sodium which leads toward the development of $3 d$ transition metal oxides $^{51}$. ( $\left.\mathrm{M}_{x} \mathrm{O}, \mathrm{M}=\mathrm{Fe}, \mathrm{Co}, \mathrm{Ni}, \mathrm{Mn}, \mathrm{Cu}\right)$. These materials are able to incorporate more than one $\mathrm{Na}^{+}$per metal through conversion reactions giving higher capacities in comparison to carbon anodes ${ }^{51}$. During discharge, $\mathrm{Na}^{+}$ion is extracted ${ }^{52}$ from the internal layered of graphite, those passes through the electrolyte ${ }^{63}$ and intercalated between the $\mathrm{NaCoO}_{2}$ compounds Figure.2.

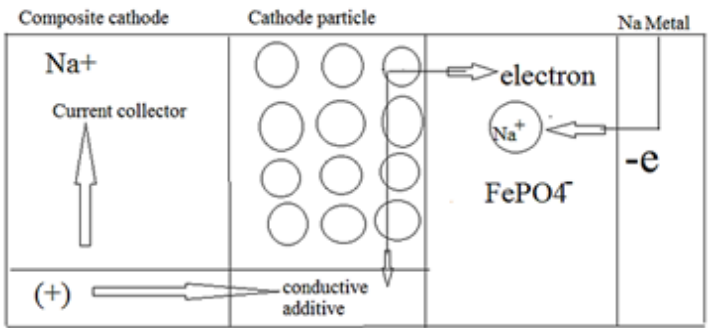

Fig. 1. the cathode conduction during charge

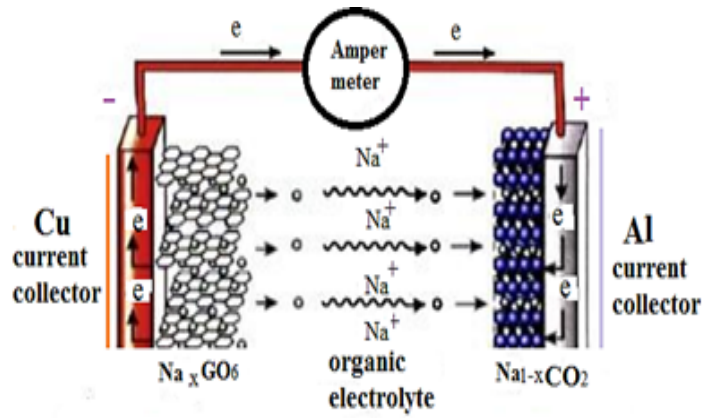

Fig. 2a. Typical commercial sodium-ion battery, the reversible process is: $m \mathrm{C}+\mathrm{NaCoO}_{2} \mathrm{Na}_{n} \mathrm{C}_{m}$ $+\mathrm{Na}_{1-\mathrm{n}} \mathrm{CoO}_{2}$

Carbon-sodium anodes have much lower gravimetric and volumetric energy densities than pure sodium which lead towards the development of interstitial-free $3 d$ transition metal oxides

\section{Electron density profiles}

It has been defined ${ }^{53}$ as $\rho(r)=\eta_{i} \phi_{i}(r) k=\sum_{i} \eta_{i} \sum_{i} C_{1, i} \chi_{i}(r) k^{k}$ (1). Where $\eta_{l}$ is occupation ${ }^{64}$ orbitals (i), $\varphi$ is the wave functions of the orbitals, $\chi$ and $C$ are basis function and coefficient matrix respectively. Atomic units can be explicitly rewritten as follows $\left(e / B^{2} h r^{3}\right) . \quad \nabla \rho(r)=\left[\frac{(a \rho(r))^{2}}{a(x)}+\frac{(a \rho(r))^{2}}{a(y)}+\frac{\left.(a \rho(r))^{2}\right]}{a(z)} \frac{1}{2}\right.$ $\nabla^{2} \rho(r)=\underline{a^{2} \rho(r)}+\underline{a^{2} \rho(r)}+\underline{a^{2} \rho(r)} \quad \begin{gathered}a(x) \\ (3)^{53-55} \text {. Electron localization }\end{gathered}$ and chemical reactivity has been described by Bader ${ }^{66}$.

\section{Hamiltonian kinetic energy density $\mathbf{K}(\mathbf{r})$}

It is defined, since the expected values of kinetic energies operator $\left\langle\varphi-\left(\frac{1}{2}\right) \nabla^{2} \varphi>\right.$ can be rewritten by definitions ${ }^{53}$. One of commonly used definition ${ }^{55}$ is: $k(r)=1 / 2 \Sigma_{i} \eta_{i} \phi_{i}(r) \nabla^{2} \phi_{i}(r)$ (4) " $G(r)$ " is a positive definition of kinetic energy densities. $G(r)=\frac{1}{2} \sum_{i} \eta_{i} \mid \nabla\left(\phi_{i} k^{2}=\frac{\sum_{2}}{2} \eta_{i}\left\{\left[\frac{(a \phi(r))^{2}}{a(x)} \quad \frac{(a \phi(r))^{2}}{a(y)} \quad \frac{(a \phi(i)))^{2}}{a(z)} \quad(5) . K(r)\right.\right.\right.$ and $G(r)$ are related to Laplacian electrons density ${ }^{55}$ $\frac{1}{4} \nabla^{2} \rho(r)=G(r)-\kappa(r)(6)$.

\section{ELF or Electronic localization function}

Becke and Edgecombe ${ }^{57}$ exhibited that spherically averages like-spin pair probability ${ }^{56,57}$ are localization functions (ELF). ELF(r) $=\overline{1+\left[D(r) / D_{o(r)}\right]^{2}}(7)$ where $\mathrm{D}(\mathrm{r})=\frac{1}{2} \sum_{i} \eta_{i} \nabla \varphi_{i}{ }^{2}-\frac{1}{8}\left[\frac{\nabla \rho_{\alpha}{ }^{2}}{\rho_{\alpha}(r)}+\frac{\nabla \rho_{\beta}{ }^{2}}{\beta(r)}(8)\right.$ and (9) for $\mathrm{D}_{\mathrm{o}(\mathrm{r})}=\frac{3}{10}\left(6 \pi^{2}\right)^{\frac{2}{8}}\left[\rho_{\mathrm{a}}(\mathrm{r}) \frac{5}{8}+\rho \beta(r) \frac{5}{]_{8}}\right.$ close-shell system, since $\rho_{\alpha}(n)-\rho_{\beta}(n)-\frac{1}{2} \rho \quad(10), \quad \mathrm{D} \quad$ and $\mathrm{D} 0$ terms can be simplified as $D(r)=\frac{1}{8} \sum_{i} \eta_{i} \nabla \phi_{i}^{2-\frac{1}{2}} \frac{\left[\nabla \rho^{2}\right]}{\rho(r)}(11)$, $D_{o(r)}==\frac{3}{10}\left(3 \pi^{2}\right) \frac{2}{3} \rho(r) \frac{5}{3}$ (12).Savin et al., have reinterpreted ${ }^{67,68}$ ELF is a meaningful ${ }^{68,69}$ for Kohn-Sham ${ }^{69,70}$ DFT or even post-HF wave-function ${ }^{58}$.

$\mathrm{LOL}$ is the other function in tight localization regions ${ }^{68}$ same as ELF, Schmider \& Beckepaper ${ }^{59,60}$. $L O L(r)=\frac{\tau(r)}{1+\tau(r)}(14)$, where $(r)=\frac{D_{0}(r)}{\frac{1}{2} \sum_{i} \eta_{i} \nabla \varphi_{i}{ }^{2}}(13)$, Do(r)for spin-polarized and close-shell systems as the same way as in ELF61.

\section{Local Information entropy}

This entropy is defined as exclusive spaces through minimizing informationentropy ${ }^{62}$ by Parr et al., ${ }^{63,64}$.The formula of Shannon's information $^{64}$ entropies for normalized and continuous probabilities function is $\mathrm{S}=-\int \mathrm{P}(\mathrm{x}) \ln \mathrm{P}(\mathrm{x}) \mathrm{d} \mathrm{x}(15) . \mathrm{S}(\mathrm{r})=\mathrm{S}(\mathrm{r})=-\frac{\rho(r)}{N} \ln \frac{\rho(r)}{N}(16)$.

\section{Electrostatic potential (ESP)}

The total electrostatic potential measures the set of functions as GIPF ${ }^{75}$ which for the molecular surfaces and macro properties ${ }^{65,66}$. There are a lot of reviews on ESP, interested readers are suggested to consult ${ }^{66,} 67$.

It is accurate in normal cases. Reduced -density -gradient or RDG and Sign $(\lambda 2)^{*} \rho$ are a couple parameter for revealing of the weak interaction region ${ }^{68}$. The basic applications are 
exemplified in Sections 4.100.1 and 4.200.1. RDG is defined as $R D G(r)=\frac{1}{2\left(3 \pi^{2}\right)^{\frac{1}{3}}} \frac{\nabla \rho(r)}{\rho(r)^{\frac{4}{3}}}(17)$ By default $x$ is 0.05 , it can be nullify this treatment by setting the parameter to zero $\rho^{\text {pro }}(r)=\Sigma_{A} \rho_{A}^{\text {free,fit }}\left(r-R_{A}\right)$ Where $\rho_{A}^{\text {free fit }}(18)$ is an averaged electron density of atom $A$.

\section{Computational details}

Calculations are performed using both Gaussian and GAMESS-US packages ${ }^{68}$. Pm6, Extended-Huckel and Pm3MM including pseudo=lanl2 calculations ${ }^{69}$.

M06 and m06-L (DFT) functional is based on pseudo-potentials ${ }^{69-70}$. The $(\mathrm{PBE})^{71}$ exchangecorrelations functional are made via minimization of the whole energy ${ }^{69-71}$. We employed DFT with the van der Waals densities for modeling the van der Waals capacitor ${ }^{72}$ in the medium-range ${ }^{73}$ interactions such as the interactions ${ }^{74}$ of two cylinders. In some further calculation the interaction energy between $x$ sodium and GO sheets. The interaction energy was calculated via the Mp6 method in all items according to $\Delta \mathrm{E}_{\mathrm{s}}(\mathrm{ev})=$ $\left\{\mathrm{E}_{\text {total }}-\left(\mathrm{E}_{\mathrm{xNa}}+\mathrm{E}_{\mathrm{GOsheets}}\right)\right\}+\mathrm{E}_{\mathrm{BSSE}}$ Where the $\Delta \mathrm{E}_{\mathrm{S}}$ is the stability energy of system ${ }^{73}$.

\section{RESULT AND DISCUSSION}

The Laplacian of electron density via Eqs $(7,8)$ for the sodium diffused in the GO system which are arranged and listed in Table.1. We have used $\rho^{s}(r)=\rho^{a}(r)-\rho^{\beta}(r)$ then the polarization-spin valuable will be replaced instead of spin densities $\xi(r)=\frac{\rho^{a}(r)-\rho^{\beta}(r)}{\rho^{a}(r)+\rho^{\beta}(r)}$
ELFs, Localized locators (LOLs) and Local Entropies including ESP charges, potential energies, of two graphene layers (GO sheets) have been listed in tables1-2 and these data have been plotted in seven figures figs.1-7.The values of yielded from zero to the local region of un-polarized cases, are shown as a complete polarized situation and are listed in (Table1).

Kintic energies, Lagrangien kintic energies densities, and the electrostatic potentials can be calculated as eqs. (9), (10) and: $V_{\text {nuc }}(r)=\sum_{A} \frac{z_{A}}{r-R_{A}}$ where RA and $Z A$ denotes vectors charges of atom $A$, and are listed in tables 1,2 .

If pseudo-potentials are used, $Z$ is shown the explicitly expression of those electrons. $Z$ can be stand for the atomic charges (the fourth column), at this item is useful for analyzing the differences between exact electrostatic potential and the electrostatic potential reproduced by atomic charges. Notice that at nuclear positions, this function will be infinite and may cause some numerical problems in program; hence at these cases this function always returns 1000 instead of infinity.

In which the actual kinetic energy term in $D(\mathbf{r})$ from eqs. $15-16$ is replaced by Kirzhnits type gradient expansions, which is $\frac{1}{2} \sum_{i} \eta_{i} \nabla \varphi_{i}{ }^{2} \approx D_{0}(r)+\frac{1}{72} \frac{\nabla \rho^{2}}{\rho(r)+\frac{1}{6} \nabla^{2} \rho(r)}$ so that ELF is the kinetic energy term.

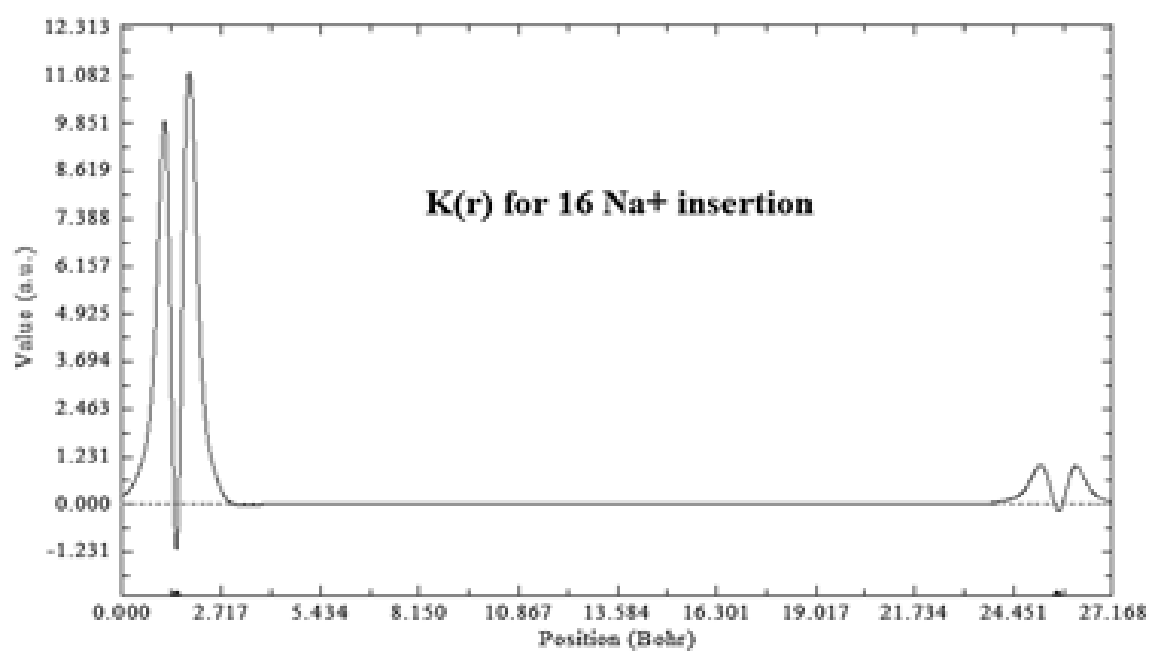



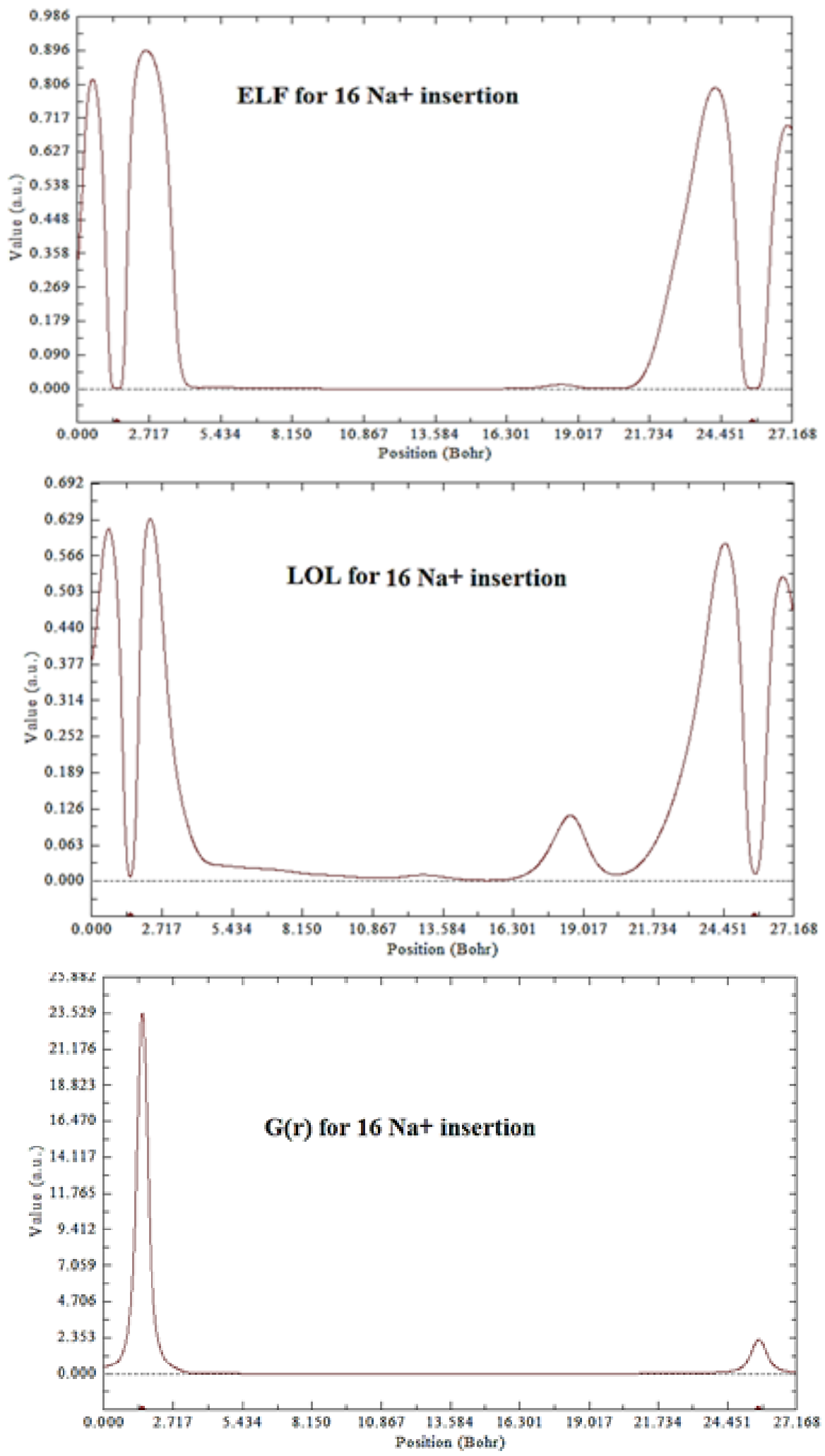

Fig. 3. ELF, LOL, $K(r)$ and $G(r)$ for $16 \mathrm{Na}+$ insertion between two layers of $\mathrm{GO}$ sheets 
MONAJJEMI et al., Orient. J. Chem., Vol. 34(2), 981-992 (2018)
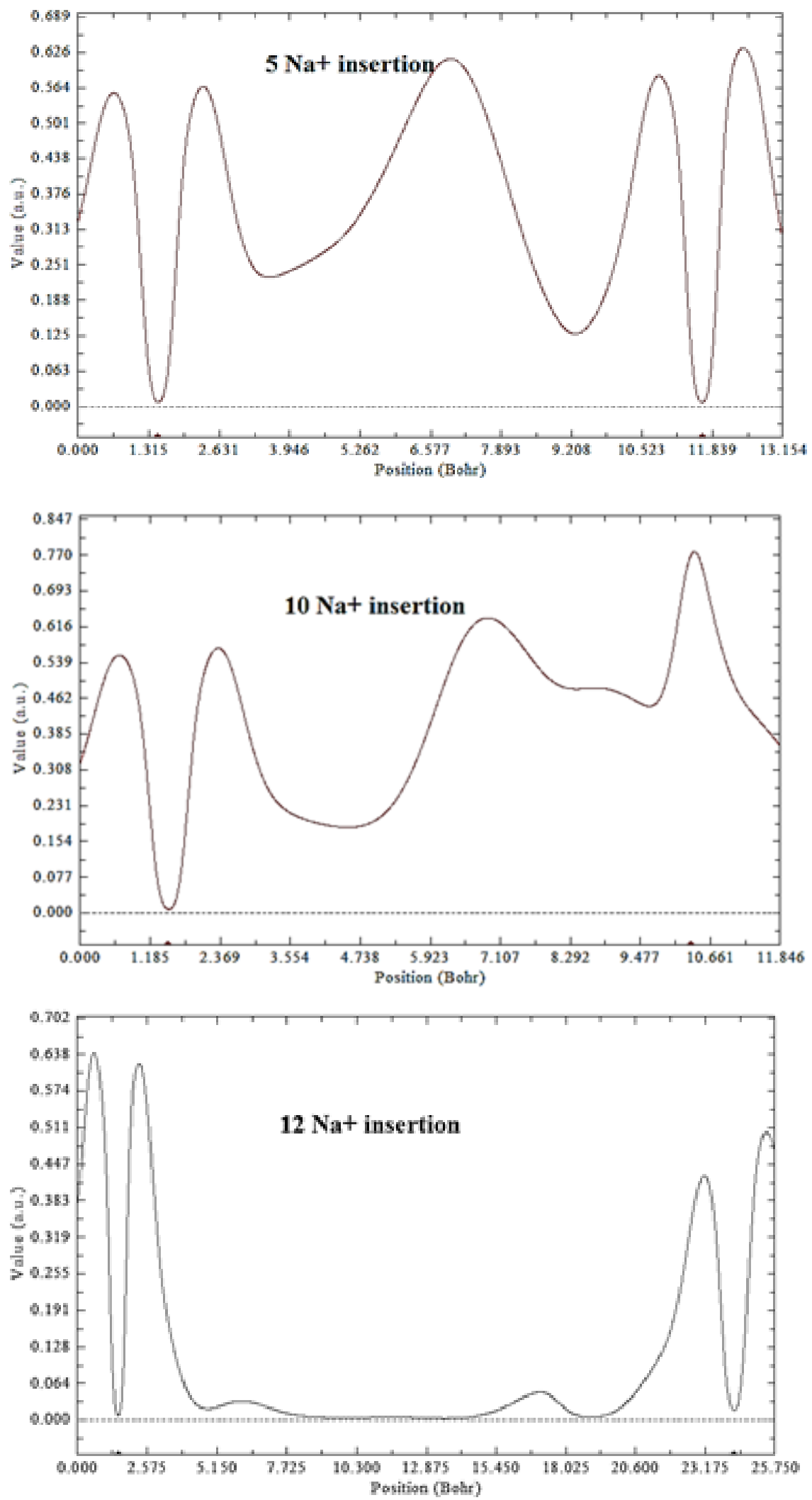


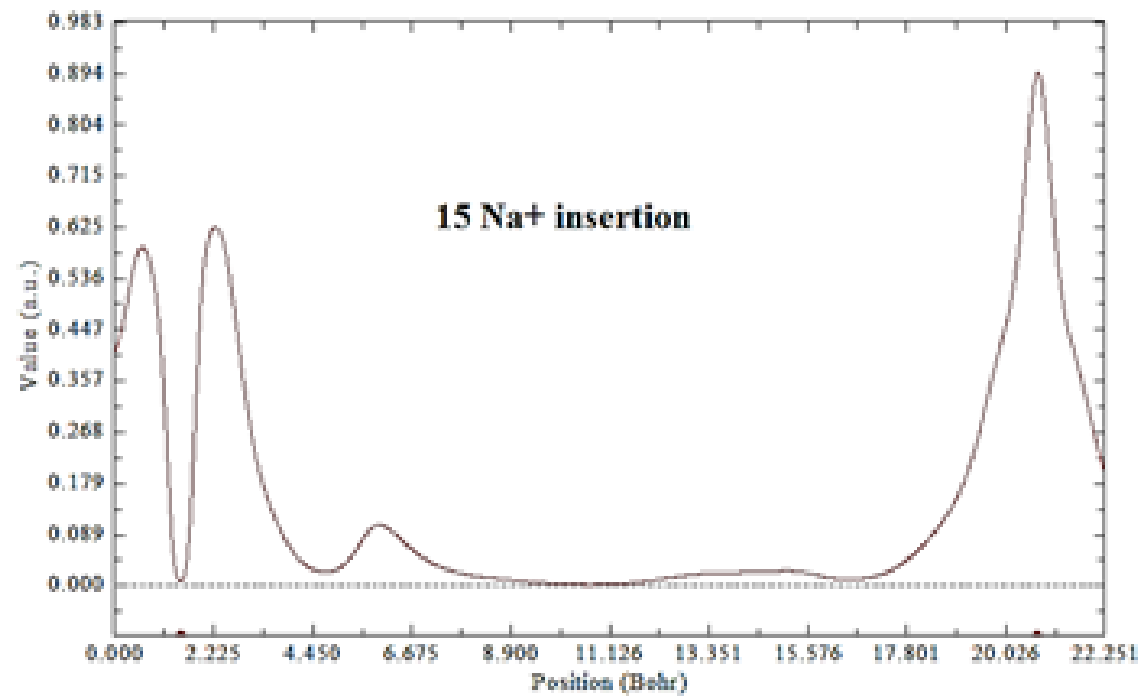

Fig. 4. LOL for various insertion of $\mathrm{Na}+$ between two layers of GO

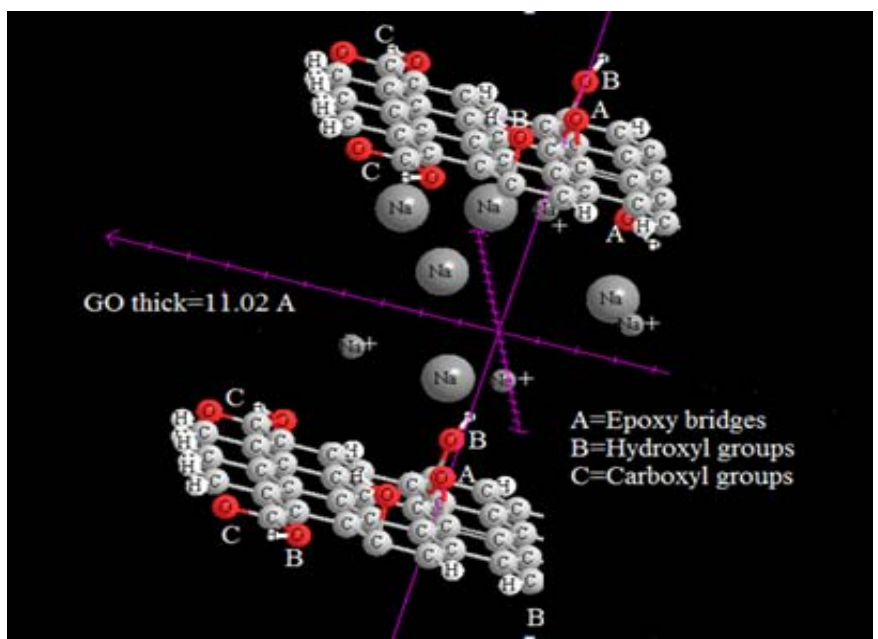

Fig.5. Sodium and Ion sodium diffusion between two GO layers

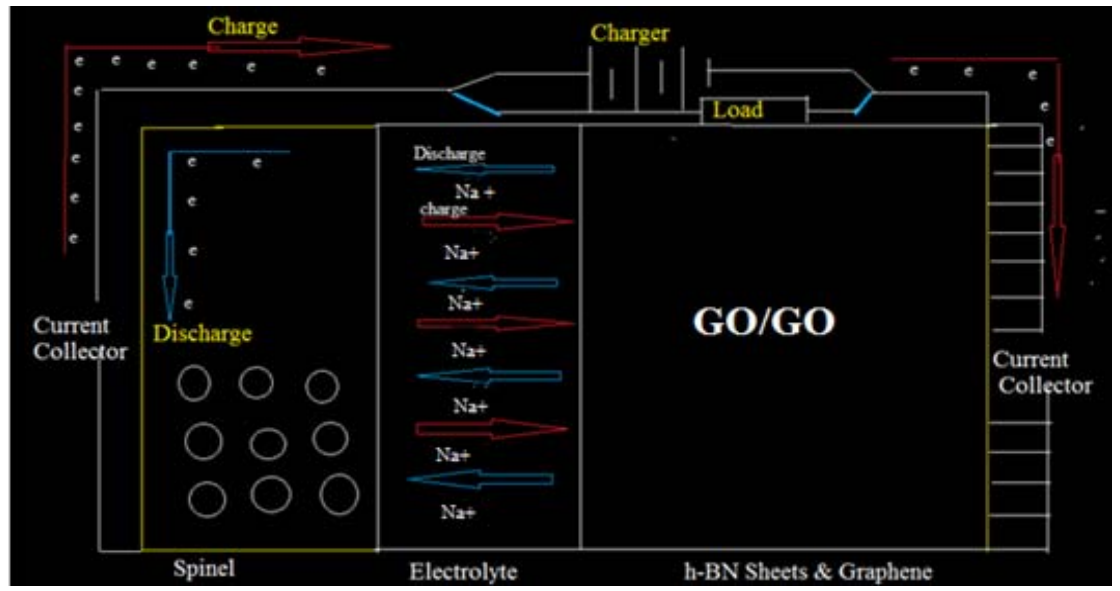

Fig. 6. Operating Na-ion battery 


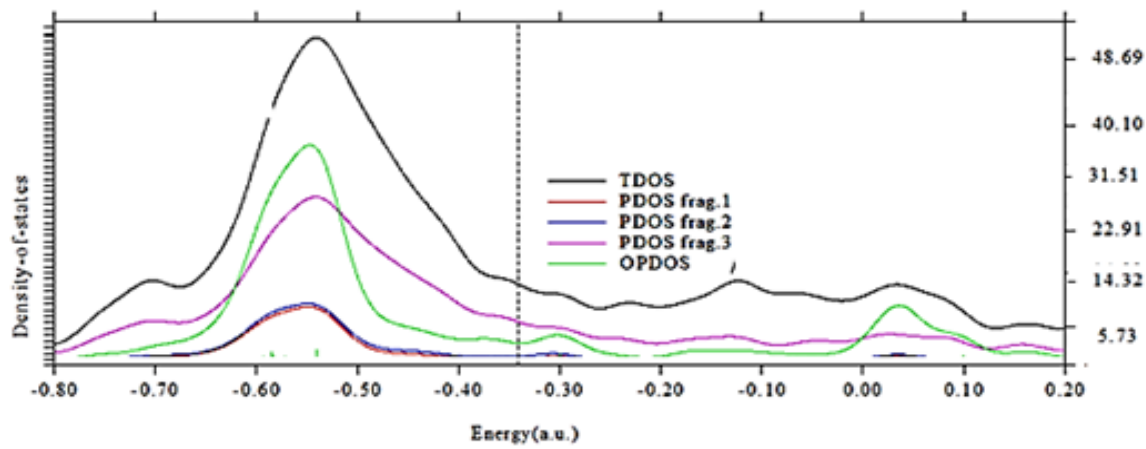

Fig. 7. Density of state plot of " 5 " sodium has been calculated of diffusion inside GO

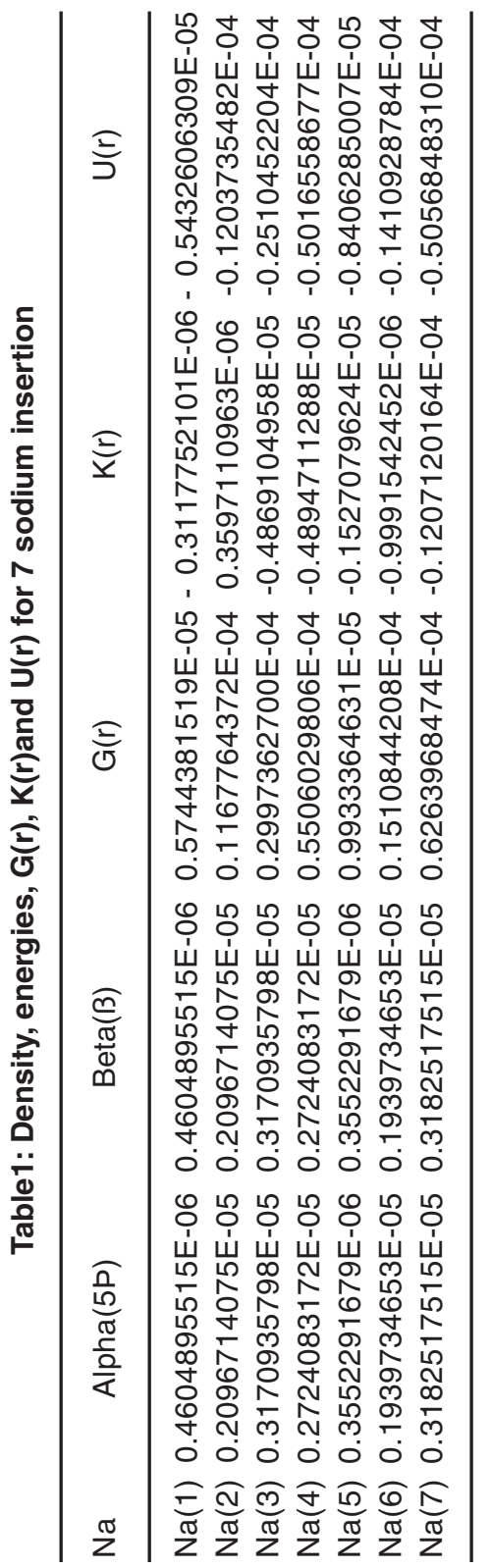

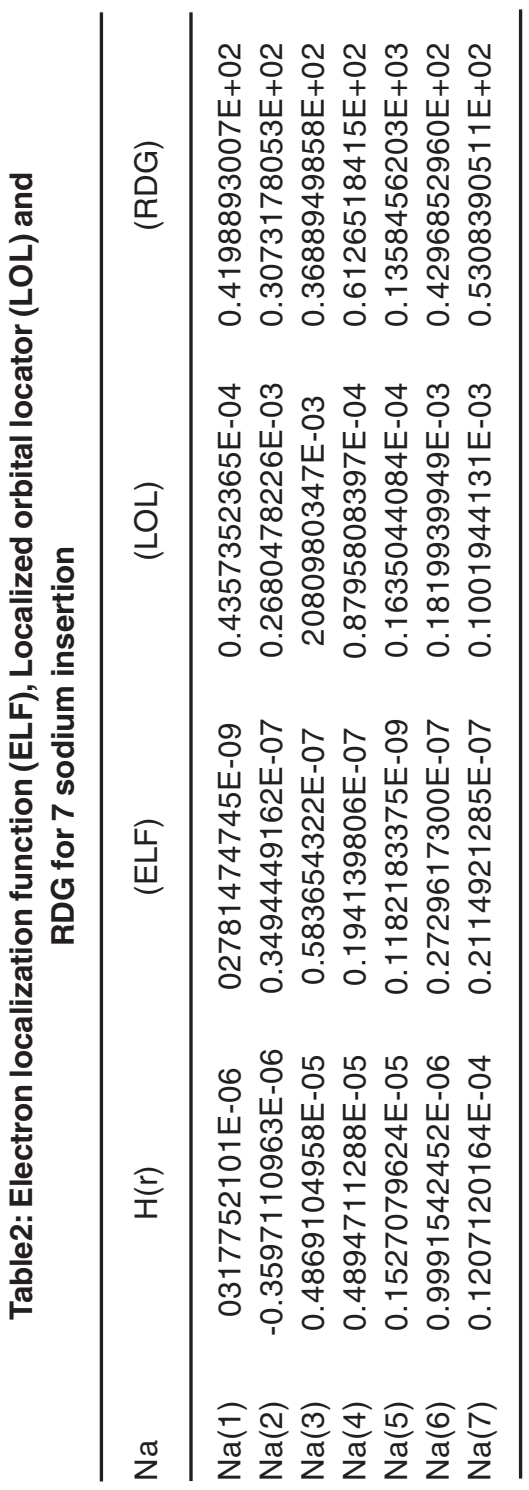


In this work we have calculated the local information entropies for each sodium atom via eqs. 19-20 and the integrating of this function over total space yields the entropy. The calculated data for local entropy are listed in Tables 2-5

Weak interactions (eqs 20-21) have significant influences for conformational structures of the macromolecules, however reproduction by the electron density via ab initio.

As sodium have unpaired electrons, leading to a difference in spin-up \& down, when two sodium atoms are adsorbed.

As a result, spin polarized cluster for NIBTs have a gap which size depends on adsorbed spin polarization. And this system can be replaced with LIBTs completely with high performance.

\section{CONCLUSION}

In conclusion, our calculations have been designed to study the $\mathrm{Na}$ adsorption on graphene oxide with two layers of GO. Our results exhibit that adsorption in $\mathrm{GO}$ is much stronger than pristine graphene.

Additionally, it has been found the structure of $\mathrm{GO}$ can be to improve the electrical transport in NIBs. Therefore, the modification and design of GO structure provide strategies for improving the performance of GO-based anodes. With the increase in defect density by GO sheets, maximum capacities obtained are much higher than that of graphite.

\section{REFERENCES}

1. Z. G. Yang, J.L.Zhang, M.C.W. Kintner-Meyer, X. C. Lu, D.W. Choi, J. P. Lemmon, and J. Liu, Chem. Rev., 2011, 111, 3577-3613.

2. P. Barpanda, G. Oyama, S.-I. Nishimura, S.-C. Chung and A. Yamada, Nat. Commun. 2014, 5, 4358.

3. M. D. Slater, D. Kim, E. Lee and C. S.
Johnson, Adv. Funct. Mater. 2013, 23, 947.

4. N. Yabuuchi, K. Kubota, M. Dahbi and S. Komaba, Chem.Rev. , 2014, 114, 11636.

5. P. Ge and M. Fouletier, Solid State Ionics., 1988, 28, 1172.

6. D. Stevens and J. Dahn, J. Electrochem. Soc., 2001, 148, A803.

7. Y. Mizutani, T. Abe, M. Inaba and Z. Ogumi, Synth. Met., 2001, 125, 153.

8. D. Stevens and J. Dahn, J. Electrochem. Soc., 2001, 148, A803.

9. D. Stevens and J. Dahn, J. Electrochem. Soc., 2000, 147, 1271.

10. Schniepp, H. C.; Li, J. L.; McAllister, M. J.; Sai, H.; Herrera-Alonso, M.; Adamson, D. H.; Prud'Homme, R. K.; Car, R.; Saville, D. A.; Aksay, I. A. The Journal of Physical Chemistry., 2006, B 110 (17), 8535-8539.

11. Pandey, D.; Reifenberger, R.; Piner, R.. Surface Science., 2008, 602(9), 1607.

12. Talyzin, A. V.; Szabó, T. S.; DéKáNy, I.; Langenhorst, F.; Sokolov, P. S.; Solozhenko,
V. L. The Journal of Physical Chemistry C ., 2009, 113(26), 11279.

13. M. Daniela C, K. Dmitry V, B. Jacob M,S. Alexander, S. Zhengzong, S. Alexander, A. Lawrence B, L. Wei, T. James. ACS Nano., 2010, 4 (8), 4806-4814.

14. Kumar, Harish V.; Woltornist, Steven J.; Adamson, Douglas H. Carbon., 2015, 10, 083.

15. T. Suzuki, T. Hasegawa, S. R. Mukai, and H. Tamon, Carbon., 2003, 41, 1933-1939

16. T. Hasegawa, T. Suzuki, S. R. Mukai, and H. Tamon, Carbon., 2004, 42, 2195-2200.

17. M. Noel, and V. Suryanarayanan, Journal of Power Sources., 2002, 111, 193-209.

18. J. L. Tirado, Materials Science and Engineering R., 2003, 40, 103-136.

19. L.J. Fu, H. Liu, C. Li, Y.P. Wu, E. Rahm, R. Holze, and H.Q. Wu, Solid State Sciences., 2006, 8, 113-128.

20. E. Frackowiak, and F. Béguin, Carbon., 2002, 40, 1775-1787.

21. M. S. Whittingham, and A.J. Jacobson (Eds.), Intercalation Chemistry, Academic Press., 1982.

22. S.A. Safran, and D.R. Hamann, Physical Review Letters., 1979, 42 (21), 1410-1413.

23. M.D. Levi, D. Aurbach, J. Maier, Journal of Electroanalytical Chemistry., 2008, 624, 251-261.

24. H. Zabel, S. A. Solin (Eds.), Graphite Intercalation Compound I, Springer-Verlag., 1990. 
25. Y.P. Wu, E. Rahm, and R. Holze, Journal of Power Sources ., 2003, 114, 228-236.

26. J.K. Lee, K.W. An, J.B. Ju, B.W. Cho, W.I. Cho, D. Park, and K.S. Yun, Carbon ., 2001, 39, 1299-1305.

27. C. De las Casas, and W.Z. Li, J. Power Sources., 2012, 208, 74-85.

28. K.S. Novoselov, A.K. Geim, S.V. Morozov, D. Jiang, Y. Zhang, S.V. Dubonos, I.V. Grigorieva, and A.A. Firsov, Science., 2004, $306,666-669$.

29. B. Partoens, and F.M. Peeters, Physical Review B ., 2006, 74, 075404-1-075404-11.

30. Monajjemi, M.; Lee, V.S.; Khaleghian, M.; B. Honarparvar, B.; F. Mollaamin, F. J. Phys.Chem C., 2010, 114, 15315.

31. Monajjemi, M. Struct Chem. 2012, 23,551-580.

32. Monajjemi, M.; Boggs, J.E. J. Phys. Chem. A., 2013, 117, 1670 "1684.

33. Monajjemi, M. Chemical Physics., 2013, 425, 29-45.

34. Monajjemi, M.; Wayne Jr, Robert. Boggs, J.E. Chemical Physics., 2014, 433, 1-11.

35. Tahan, A. Acta Biotheor., 2011, 59, 291-312.

36. Mollaamin, F.; Monajjemi, M. Physics and Chemistry of Liquids., 2012, 50(5) 2012, 596-604.

37. Khosravi, M.; Honarparvar, B.; Mollaamin, F.; International Journal of Quantum Chemistry., 2011, 111, 2771-2777.

38. Monajjemi, M. Theor Chem Acc, 2015, 134:77 DOI 10.1007/s00214-015-1668-9.

39. Monajjemi, M. Journal of Molecular Modeling., 2014, 20, 2507.

40. Monajjemi, M. Biophysical Chemistry., 2015, 207,114 -127.

41. Jalilian,H.; Monajjemi, M. Japanese Journal of Applied Physics., 2015, 54(8) 08510

42. Majid Monajjemi *, Samira Bagheri, Matin S. Moosavi, Nahid Moradiyeh, Mina Zakeri, Naime Attarikhasraghi, Nastaran Saghayimarouf, Ghorban Niyatzadeh, Marzie Shekarkhand, Mohammad S. Khalilimofrad, Hashem Ahmadin and Maryam Ahadi, Molecules., 2015, 20, 2163621657; doi:10.3390molecules 201219769.

43. Monajjemi, M, Journal of Molecular Liquids., 2017, 230, 461-472.

44. D.S. Wilkinson, Mass Transport in Solid and Fluids, Cambridge University Press., 2000.
45. H. Mehrer, Diffusion in Solids, Springer, 2007, 27-36.

46. D.A. Porter, K.E. Easterling, Phase Transformations in Metals and Alloys, 2nd edition, Chapman \& Hall, 1992, 1-109 .

47. R.H. Petrucci, W.S. Harwood, General Chemistry, 7th edition, Prentice-Hall, 1997, pp. 315-343.

48. H. Dehmelt, Physica Scripta., 1998, 22. 102-110 .

49. C. Wang, and J. Hong, Electrochemical and Solid-State Letters., 2007, 10 (3) A65-A69.

50. R.A. Huggins, in: C.A.C. Sequeira, A. Hooper (Eds.), Proceedings of the NATO. Advanced Study Institute on Solid State Batteries, Alcabideche, Portugal, 1984, 2-17.

51. P. Poizot, S. Laruelle, S. Grugeon, L. Dupont, and L.J.M. Tarascon, Nature., 2000, 407, (6803), 496-499.

52. A.V. Churikov, N.A. Gridina, N.V. Churikova, in: V. Igor, Barsukov, S.Christopher, Johnson, E. Joseph, Doninger, Z. Vyacheslav, Barsukov (Eds.), New Carbon Based Materials for Electrochemical Energy Storage Systems, Springer., 2006, 269-276.

53. T. Lu, F. Chen, Acta Chim. Sinica., 2011, 69, 2393-2406 .

54. T. Lu, F. Chen, J. Mol. Graph. Model., 2012, 38, 314-323.

55. T. Lu, F.Chen Multiwfn: A Multifunctional Wave-function Analyzer, J. Comp. Chem., 2012, 33, 580-592.

56. R.F.W. Bader, Atoms in Molecule: A quantum Theory (Oxford Univ. press, Oxford., 1990.

57. Becke and Edgecombe, J. Chem. Phys., 1990, 92, 5397.

58. A. Savin, Angew. Chem. Int. Ed.Engl.,1992, 31, 187.

59. V.G. Tsirelson, Yu.A. Abramov. Chem. Phys. Lett., 2002, 351, 142-148.

60. H.L. Schmider,A.D. Becke J Mol Struct, Theochem.,2000, 527,5150 .

61. Jacobsen Can. J. Chem., 2008, 86(7), 695.

62. C. Aslangul, R. Constanciel, R. Daudel and P. Kottis. Adv. Quantum Chem ., 1972, 6,93.

63. R.G.Parr, P.W.Ayers, R.F.Nalewajski J Phys Chem A., 2005, 109, 3957-3959.

64. S. Noorizadeh and E. Shakerzadeh, Phys. Chem. Chem. Phys., 2010, 12, 4742. 
65. J. S. Murray, and P. Politzer, J. Mol. Struct. (Theochem)., 1994, 307, 55.

66. J. S. Murray Comput. Mol. Sci., 2011, 1, 153 .

67. P. Politzer, J. S. Murray, Theor. Chem. Acc., 2002, 108, 134.

68. M.W. Schmidt, K.K.Baldridge, J.A.Boatz, S. T. Elbert, M. S. Gordon, J . H. Jensen, S. Koseki, N. Matsunaga, and K. A. Nguyen ., 2004,14(11) 1347-1363.

69. Yan Zhao, Donald G. Truhlar, Theor Chem Account ., 2008, 120, 215-241.

70. W. Kohn, L. J. Sham, Phys. Rev., 1965, 140, 1133-1138.

71. J.P. Perdew, K.Burke, Ernzerhof, Phys. Rev. Lett., 1996, 77, 3865-3868.

72. D. L. Klein, R. Roth, A. K. L. Lim, A. P. Alivisatos, and P. L. McEuen, Nature, 1997, $389-699$.

73. Yan Zhao, Donald G. Truhlar, Accounts of
Chemical Research., 2008, 41(2) 157-167.

74. B.H. Besler, K.M. Merz, P.A. Kollman, J. comp. Chem. 1990, 11, 431.

75. L.E. Chirlian, M. M. Francl, J.comp.chem., 1987, 8, 894.

76. Brneman GM, Wiberg KB J. Comp Chem., 1990, 11, 361.

77. 28. Jalilian, $\mathrm{H}$.; Monajjemi, M.; Aghaei, $\mathrm{H}$, Orient. J. Chem., 2017, 33(5) 2179-2187.

78. Raoufi, F.; Aghaie, H.; Orient. J. Chem., 2017, 33(5), 2542-2550.

79. Mohammadian ,N.; Zare, K.; Monajjemi, M.; Orient. J. Chem., 2017, 33(4),1595-1602

80. Chitsazan,A.; Monajjemi, M.; Aghaei, H.; Sayadian, M.; Orient. J. Chem, 2017., 33 (3), 1366-1374.

81. Moosavi, M.S.; Monajjemi, M.; Zare, K.; Orient. J. Chem., 2017, 33(4) 1648-1658. 